\title{
Polysiloxane/PVA-glutaraldehyde hybrid composite as solid phase for immunodetections by ELISA
}

\author{
A.E. Lima Barros ${ }^{1}$, \\ A.M.P. Almeida ${ }^{3}$, \\ L.B. Carvalho Jr. ${ }^{1}$ \\ and W.M. Azevedo ${ }^{2}$
}

\author{
${ }^{1}$ Laboratório de Imunopatologia Keizo Asami and Departamento de Bioquímica, \\ Universidade Federal de Pernambuco, Recife, PE, Brasil \\ 2Laboratório de Química do Estado Sólido, Departamento de Química Fundamental, \\ Universidade Federal de Pernambuco, Recife, PE, Brasil \\ ${ }^{3}$ Centro de Pesquisas Aggeu Magalhães, FIO CRUZ, Recife, PE, Brasil
}

\section{Correspondence \\ L.B. Carvalho Jr. \\ Laboratório de Imunopatologia \\ Keizo Asami, UFPE \\ 50670-420 Recife, PE \\ Brasil \\ Fax: + 55-81-271-8485 \\ E-mail: Ibcj@ npd.ufpe.br \\ Research supported by $\mathrm{CNPq} /$ CTPETRO (No. 463655/001) and \\ the Japan International Cooperation Agency (IICA).}

Received May 22, 2001

Accepted February 6, 2002

\section{Abstract}

We developed an efficient method to prepare a hybrid inorganicorganic composite based on polyvinyl alcohol (PVA) and polysiloxane using the sol-gel disc technique. Antigen obtained from Yersinia pestis was covalently immobilized onto these discs with glutaraldehyde and used as solid phase in ELISA for antibody detection in serum of rabbits experimentally immunized with plague. Using $1.25 \mu \mathrm{g}$ antigen per disc, a peroxidase conjugate dilution of $1: 4,000$ and a serum dilution of 1:200 were adequate for the establishment of the procedure. These values are similar to those used for PVA-glutaraldehyde discs, plasticized filter paper discs and the polyaniline-Dacron composite discs. This procedure is comparable to that which utilizes the adsorption of the antigen to conventional PVC plates, with the amount of antigen being one fourth that employed in conventional PVC plates $(5 \mu \mathrm{g} /$ well $)$. In addition to the performance of the polysiloxane/PVA-glutaraldehyde disc as a matrix for immunodetection, its easy synthesis and low cost are additional advantages for commercial application.

The alkoxide sol-gel process is an efficient method to prepare silica glass by the hydrolysis of alkoxysilane precursors and by subsequent condensation of the remaining silanols, followed by aging and drying under ambient atmospheres and sintering. The hydrolysis and polycondensation of tetraethoxysilane is as follows:

$$
\stackrel{\mathrm{Si}(\mathrm{OEt})_{4} \underset{\text { Polycondensation }}{\longrightarrow}\left(\mathrm{SiO}_{2}\right) \mathrm{n}}{\text { Hydrolysis }} \mathrm{n}(\mathrm{EtO}) \mathrm{xSi}(\mathrm{OH}) \mathrm{y}-\mathrm{x}
$$

The advantages of this technique are the homogeneity and purity of the gels and a relatively low sintering temperature. Such

\section{Key words}

- Polysiloxane

- Polyvinyl alcohol

- Solid phase

- Immunodetection

- Yersinia pestis

- ELISA advantages are important to prepare single, massive and unchangeable glasses, thin films and optic fibers $(1,2)$. Understanding the chemical reactions in the various steps of the sol-gel process leads to a better control of the process and therefore to an improvement in the reproducibility of the final product (3-5). The sol-gel technique also is an excellent method to prepare hybrid material. The low temperature synthesis enables organic or inorganic species to be incorporated into rigid silicon oxide matrices without degradation. The resulting composite combines the chemical and physical properties of the guest with 
an excellent optic, thermal, and chemical stability of the host silicon oxide matrices.

Hybrid inorganic-organic composites derived by sol-gel processing are materials that can potentially be designed for a wide range of applications. Structural diversity is achieved by controlling the relative ratio of organic versus inorganic content, the level of structural complexity of the organic component and its chemical nature, the chemical composition of the inorganic precursor molecule, and the reaction condition used to synthesize the composite. Thus, this synthetic framework offers the promise of engineered multicomponent composite material designed for specific desired applications. Since the surprising discovery of Braun et al. (6) that active protein can be entrapped in a sol-gel matrix without losing its activity, solgel-derived glass has emerged as a new class of material well suited for the immobilization of biomolecules. This inorganic material is particularly attractive for the fabrication of biosensors since it possesses physical rigidity, chemical inertness and high photochemical and thermal stability and experiences negligible swelling in aqueous and organic solvents. However, the wettability of some glass materials is not high, and depends on the silica-forming monomers. It is well known that neither highly hydrophobic nor totally hydrophilic matrices are desirable for sensing applications. In the former matrix, the analyte cannot approach the embedded enzyme, and the latter exhibits a large background current in amperometric biosensors. When chemical modifiers such as metal dispersion, water-soluble polymers, and proteins were added to the material, the resulting composite became more hydrophilic.

This paper describes the synthesis of small discs of a polysiloxane-polyvinyl alcohol (PVA) composite prepared by the sol-gel technique in order to provide a more biocompatible microenvironment and a more suitable surface for covalent immobiliza- tion. A chemical arm was later introduced through the glutaraldehyde molecule by acid catalysis (7). Free chemical groups were still available by which proteins could be covalently fixed. Antigen from Yersinia pestis was used as a model to evaluate the biological properties of retention of these immobilized proteins. Therefore, this antigen-composite disc derivative was used in ELISA to detect anti-F1 IgG in serum from immunized rabbit.

Polysiloxane-PVA disc preparation. The hybrid composite was synthesized by preparing a mixture of $5 \mathrm{ml}$ tetraethoxysilane (Aldrich, Milwaukee, WI, USA), $5 \mathrm{ml}$ ethanol (Aldrich) and $6 \mathrm{ml}$ of a $2 \%$ (w/v) solution of PVA (MW 72,000, Reagen, Rio de Janeiro, RJ, Brazil). The reagents were carefully added and two or three drops of concentrated $\mathrm{HCl}$ were added in order to catalyze the reaction. The solution was stirred for $5 \mathrm{~min}$ at $60^{\circ} \mathrm{C}$ and aliquots $(10 \mu \mathrm{l})$ of the mixture were then transferred to microwells of tissue culture plates (disc shape) to complete the reaction. The molds remained closed for 10 days and were then opened until they no longer exhibited weight loss due to evaporation of residual water and solvent. The polysiloxanePVA discs were then kept in $0.067 \mathrm{M}$ sodium phosphate buffer, $\mathrm{pH} 7.2$, at $4-10^{\circ} \mathrm{C}$ until use.

Polysiloxane-PVA sensitization. The polysiloxane-PVA discs were introduced into microwells of tissue culture plates and treated with $2.5 \%(\mathrm{w} / \mathrm{v})$ glutaraldehyde (Riedel) and $10 \mathrm{mM} \mathrm{H}_{2} \mathrm{SO}_{4}$ at $28^{\circ} \mathrm{C}$ for $1 \mathrm{~h}$ and washed thrice with deionized water.

Antigen immobilization. The polysiloxane-PVA-sensitized discs were incubated with $100 \mu \mathrm{l}$ of $\mathrm{F} 1$ antigen $(5 \mu \mathrm{g})$ from $Y$. pestis obtained by the method of Baker et al. (8), prepared in $0.067 \mathrm{M}$ sodium phosphate buffer, $\mathrm{pH} 7.2$, containing $0.9 \%(\mathrm{w} / \mathrm{v}) \mathrm{NaCl}$ (PBS), at $25^{\circ} \mathrm{C}$ for $1 \mathrm{~h}$. These discs containing the covalently immobilized antigen (antigen/discs) were then washed twice with PBS containing $0.05 \%(\mathrm{w} / \mathrm{v})$ Tween 20 
(Sigma, St. Louis, MO, USA), blocked with $3 \%(\mathrm{w} / \mathrm{v})$ skim milk (Molico milk, Nestle) in PBS at $4^{\circ} \mathrm{C}$ for $12 \mathrm{~h}$, and washed once with PBS/Tween.

ELISA. The blocked antigen disc was incubated at $37^{\circ} \mathrm{C}$ for $1 \mathrm{~h}$ in $100 \mu \mathrm{l}$ of PBSdiluted serum (1:200) from immunized and non-immunized rabbits against $Y$. pestis produced at the Centro de Pesquisas Aggeu Magalhães, FIOCRUZ. The preparation was then washed 5 times with PBS/Tween and incubated in $100 \mu$ l of goat anti-rabbit IgG conjugated with horseradish peroxidase (Sigma), diluted 4,000 times in PBS at $37^{\circ} \mathrm{C}$ for $1 \mathrm{~h}$. Five washings with PBS/Tween were then carried out. The substrate solution (200 $\mu \mathrm{l})$, consisting of $0.325 \%(\mathrm{w} / \mathrm{v})$ orthophenylenediamine dihydrochloride (OPD, Sigma) and $0.085 \%(\mathrm{v} / \mathrm{v}) \mathrm{H}_{2} \mathrm{O}_{2}$ in $0.3 \mathrm{M}$ Tris-citrate buffer, $\mathrm{pH}$ 6.0, was added and incubated at room temperature $\left(28^{\circ} \mathrm{C}\right)$ for 15 min in the dark. The reaction was stopped with $2.5 \mathrm{M} \mathrm{H}_{2} \mathrm{SO}_{4}(25 \mu \mathrm{l})$. The discs were removed and the absorbance of the supernatant was read at $492 \mathrm{~nm}$ with a Microplate reader (model 550; BioRad Laboratories, Hercules, CA, USA). The above procedure was previously standardized by determining optimal conditions with respect to antigen, serum and second antibody conjugate concentrations. Samples $(100 \mu l)$ of antigenic solution containing 0.6 to $5.0 \mu \mathrm{g}$ protein were incubated with the activated discs and the antigen discs obtained were incubated with immunized and non-immunized serum $(100 \mu \mathrm{l})$ diluted 100 to 800 times. ELISA was then applied to these discs containing increasing amounts of antigen and serum and using conjugate diluted 1:4,000. ELISA using $1.25 \mu \mathrm{g}$ antigen and serum dilutions of 1:200 established the optimum dilution of goat anti-rabbit IgG conjugated with horseradish peroxidase.

Titration of goat anti-rabbit IgG conjugated with horseradish peroxidase using 1.25 $\mu \mathrm{g}$ of $\mathrm{F} 1$ antigen, immunized and non-immunized sera diluted 1:200 times and PBS as control, showed that the best dilution was attained at serum dilution 1:4,000.

Figure 1 shows the relationship between the concentration of $\mathrm{F} 1$ antigen from $Y$. pestis immobilized onto the polysiloxane-PVAglutaraldehyde composite discs using different serum dilutions and the absorbance obtained with ELISA, using goat anti-rabbit IgG conjugated with horseradish peroxidase diluted 1:4,000 times. Hyperbolic curves were obtained as expected by the nature of antigen-antibody complex formation, which follows the Michaelis-Menten equation for enzyme-substrate complex formation (9). Also, a significant difference in absorbance values was observed when comparing immunized and non-immunized serum, while values close to zero were detected for the control (PBS). From these results one can conclude that $1.25 \mu \mathrm{g}$ of antigen per composite disc is sufficient to standardize the methodology.

Therefore, ELISA using this matrix can be set up as follows: $1.25 \mu \mathrm{g}$ of F1 antigen

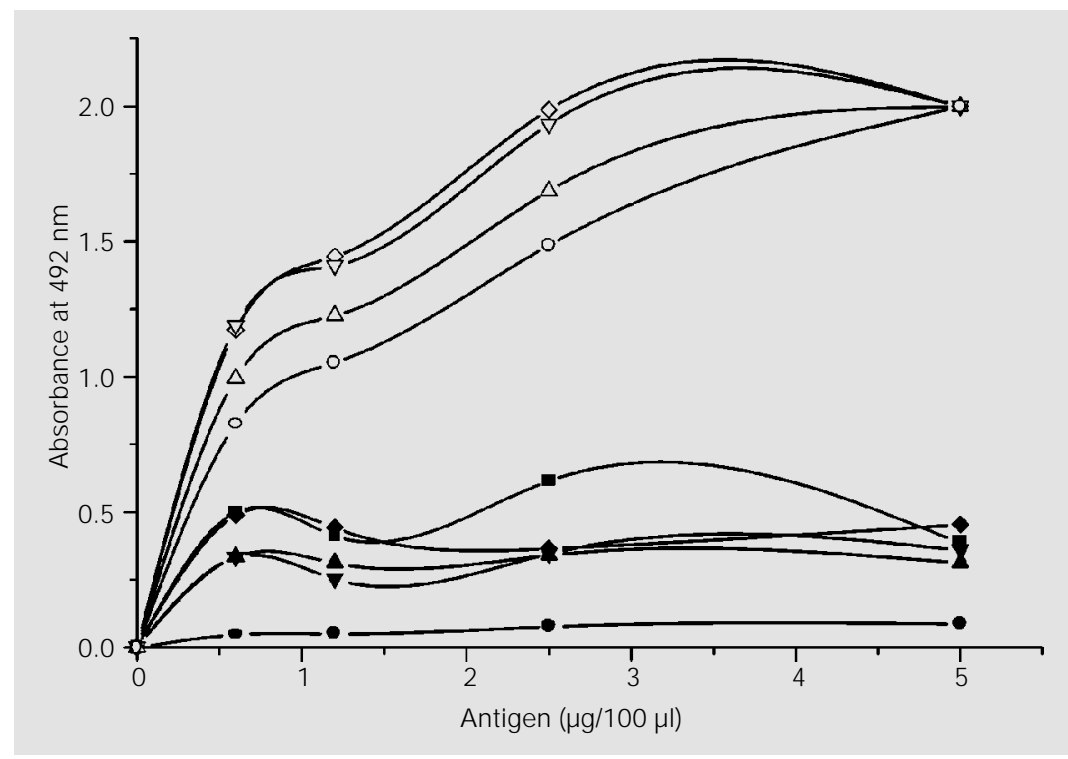

Figure 1. Relation between F1 antigen and titration of immune and non-immune rabbit serum in ELISA using polysiloxane-PVA-glutaraldehyde discs. Titration of immune serum diluted 1:100 (open lozenges), 1:200 (open inverted triangles), 1:400 (open triangles), and 1:800 (open circles). Titration of non-immune serum diluted 1:100 (filled squares), 1:200 (filled lozenges), 1:400 (filled inverted triangles), and 1:800 (filled triangles). Control - PBS (filled circles). 
for each composite-glutaraldehyde disc, 1:4,000 conjugate dilution, and 1:200 serum dilution. A comparison between this method and conventional ELISA, based on antigen adsorption onto polyvinyl chloride (PVC) plates, is shown in Table 1. Firstly, regarding the sera collected from immunized rabbits $(\mathrm{N}=8)$, mean values $( \pm \mathrm{SD})$ of $1.505 \pm 0.262$ and $1.184 \pm 0.254$ were calculated for ELISA absorbance using the composite discs and the conventional procedure, respectively. The independent $t$-test applied to these mean values showed no significant difference at the 0.05 level. A linear correlation was observed when the absorbance values for ELISA using composite discs were plotted against those obtained for the conventional procedure $(r=0.92662$ and $P=0.00093)$. For the sera collected from non-immunized rabbits $(\mathrm{N}=8)$ mean values of $0.311 \pm 0.023$ and $0.190 \pm 0.044$ were estimated for the composite discs and conventional ELISA procedures, respectively. Briefly, the performance of ELISA with F1 antigen covalently fixed on the polysiloxane-PVA-glutaraldehyde composite discs is comparable to that based on the adsorption of the antigen on PVC plates in the conventional procedure. Furthermore, the amount of antigen is one fourth that employed in the conventional PVC plates

Table 1. Comparison of ELISA using polysiloxane/polyvinyl alcohol-glutaraldehyde discs and polyvinyl chloride (PVC) as solid phases.

\begin{tabular}{lccccc}
\hline \multirow{2}{*}{ Rabbit } & \multicolumn{2}{c}{ Non-immunized } & & \multicolumn{2}{c}{ Immunized } \\
\cline { 2 - 3 } \cline { 5 - 6 } & PVC & Discs & & PVC & Discs \\
\hline 1 & 0.271 & 0.418 & & 0.735 & 1.087 \\
2 & 0.158 & 0.226 & & 1.030 & 1.146 \\
3 & 0.171 & 0.325 & & 1.080 & 1.492 \\
4 & 0.188 & 0.270 & & 1.156 & 1.527 \\
5 & 0.148 & 0.227 & & 1.229 & 1.577 \\
6 & 0.146 & 0.356 & & 1.288 & 1.680 \\
7 & 0.231 & 0.335 & & 1.359 & 1.707 \\
8 & 0.208 & 0.331 & & 1.598 & 1.825 \\
$M \pm S D$ & $0.190 \pm 0.044$ & $0.311 \pm 0.0233^{*}$ & & $1.184 \pm 0.254$ & $1.505 \pm 0.262^{*}$
\end{tabular}

*The independent t-test indicated that both mean values were significantly different $(\mathrm{P}<0.05)$.
(5 $\mu \mathrm{g} / \mathrm{well})$.

Lehtonen and Viljanen (10), studying the concentration of antigen in ELISA for the detection of chicken anti-bovine serum albumin, used three polymers as solid phase and two immobilization procedures: polystyrene and nylon (adsorption) and cyanogen bromide-activated paper (covalent link). There was a noticeable release of the adsorbed antigen during the assay from both polystyrene $(30 \%)$ and nylon (60\%). Desorption of antigen from activated paper during the assay was lower than with polystyrene or nylon. It is well known that protein release is more likely to occur from adsorbed antigens than from covalently linked preparations, particularly under extreme conditions of $\mathrm{pH}$, ionic strength and temperature.

In our laboratories other procedures for antigen covalent immobilization on supports have been proposed such as Dacron (11), ferromagnetic Dacron $(12,13)$, interpenetrated network of PVA-glutaraldehyde (1417), filter paper plasticized with PVA-glutaraldehyde (18), and a polyaniline-Dacron composite (19). The optimal values of F1 antigen amount, conjugate dilution and serum titer established for the present method $(1.25 \mu \mathrm{g} / \mathrm{disc} ; 1: 4,000$ and 3,200, respectively) can be compared to those found for PVA-glutaraldehyde $(1.3 \mu \mathrm{g} / \mathrm{disc} ; 1: 6,000$ and $1: 12,600)$, plasticized filter paper $(1.25$ $\mu \mathrm{g} / \mathrm{disc} ; 1: 12,000$ and $1: 6,400)$, and polyaniline-Dacron $(2 \mu \mathrm{g} / \mathrm{disc} ; 1: 4,000$ and $1: 800)$. Higher values for the plasticized filter paper conjugate dilution and PVA-glutaraldehyde serum dilution were due to the use of a particular second antibody preparation and immunized rabbit serum, respectively.

In addition, the performance of the polysiloxane-PVA-glutaraldehyde disc as a matrix for immunodetection, its easy synthesis and the low cost are additional advantages for commercial application. More than 1,000 discs can be synthesized at a cost of US $\$ 0.50$. The preservation of the biological properties 
of this immobilized antigenic preparation, employing the sol-gel discs as the solid phase, presents promising applications to other proteins such as enzymes, hormones and receptors. This further use of the present support is currently under investigation in our laboratories.

\section{References}

1. Hench LL \& Ulrich DR (1984). Ultrastructure Processing of Ceramics, Glasses and Composite. J ohn Wiley and Sons, New York, NY, USA.

2. Klein LC (1988). Sol-gel Technology for Thin Films, Fibers, Preforms, Electronics and Specialty Shapes. Noyes, Park Ridge, NJ , USA.

3. Schmidt $H$ (1988). Chemistry of material preparation by the sol-gel process. J ournal of Non-Crystalline Solids, 100: 51-64.

4. Boonstra $\mathrm{AH} \&$ Bernardes J NM (1988). The dependence of the gelation time on the hydrolysis time in a 2-step $\mathrm{SiO}_{2}$ solgel process. Journal of Non-Crystalline Solids, 105: 207-213.

5. Boonstra AH \& Baken J ME (1989). Hydrolysis-condensation reactions of silica gels during autoclave drying. J ournal of Non-Crystalline Solids, 109: 1-8.

6. Braun S, Rappoport S, Zusman R, Avnir D \& Ottolenghi M (1990). Biochemically active sol-gel glasses: the trapping of enzymes. Materials Letters, 10: 1-3.

7. Araujo AM, Neves J r MT, Azevedo WM, Oliveira GG, Ferreira J r DL, Coelho RAL, Figueiredo EAP \& Carvalho J r LB (1997). Polyvinyl alcohol-glutaraldehyde network as a support for protein immobilisation. Biotechnology Techniques, 11: 67-70.

8. Baker EE, Sommer H, Foster LE, Meyer E $\&$ Meyer KF (1952). Studies on immuniza-

\section{Acknowledgments}

The authors are deeply grateful to Aureci Maria de Araujo and Raquel de Andrade Lima Coêlho for support and encouragement. tion against plague. I. The isolation and characterization of the soluble antigen of Pasteurella pestis. J ournal of Immunology, 68: 131-140.

9. van-Heyningen $V$, Brock $D J \&$ vanHeyningen S (1983). A simple method for ranking the affinities of monoclonal antibodies. J ournal of Immunological Methods, 62: 147-153.

10. Lehtonen OP \& Viljanen MKJ (1980). Antigen attachment in ELISA. J ournal of Immunological Methods, 34: 61-70.

11. Montenegro SML, Silva J DB, Brito MEF \& Carvalho J r LB (1999). Dot enzymelinked immunosorbent assay (dot-ELISA) for schistosomiasis diagnosis using Dacron as solid-phase. Revista da Sociedade Brasileira de Medicina Tropical, 32: 139-143.

12. Carneiro Leão AMA, Carvalho J r LB \& Malagueño E (1994). The use of ferromagnetic Dacron as solid-phase in enzyme immunoassays. Memórias do Instituto Oswaldo Cruz, 89: 189-193.

13. Pinheiro SMP, Canvalho J r LB \& Chaves MEC (1999). The use of ferromagnetic Dacron as solid-phase in chemiluminescent assays. Biotechnology Techniques, 13: 919-922.

14. Araujo AM, Petribú ATS, Barbosa GHTS, Diniz J RP, Almeida AMP, Azevedo WM, Malagueño E \& Carvalho J r LB (1996).
The use of polyvinyl alcohol glutaraldehyde as solid-phase in ELISA for plague. Memórias do Instituto Oswaldo Cruz, 91 : 195-198.

15. Araujo AM, Barbosa GHTS, Diniz J RP, Malagueño E, Azevedo WM \& Carvalho $r$ LB (1997). Polyvinyl alcohol glutaraldehyde as solid-phase in ELISA for schistosomiasis. Revista do Instituto de Medicina Tropical de São Paulo, 39: 155-158.

16. Araujo AM, Petribu ATS, Barbosa GHTS, Diniz J RP, Almeida AMP \& Canvalho J r LB (1998). Rapid ELISA for plague. Memórias do Instituto Oswaldo Cruz, 93: 111-112.

17. Carvalho J r LB, Araujo AM, Almeida AMP $\&$ Azevedo WM (1996). The use of polyvinyl alcohol glutaraldehyde antigen coated discs for laser induced fluorescence detection of plague. Sensors and Actuators B: Chemical, 35-36: 427-430.

18. Barbosa GHTS, Santana EM, Almeida AMP, Araujo AM, Fatibello O \& Carvalho J r LB (2000). The use of filter paper plasticized with polyvinyl alcohol-glutaraldehyde in ELISA. Brazilian J ournal of Medical and Biological Research, 33: 823-827.

19. Coêlho RAL, Santos GMP, Azevêdo PHS, J aques GA, Azevedo WM \& Carvalho J $r$ LB (2001). Polyaniline-Dacron composite as solid phase in ELISA for Yersinia pestis antibody detection. J ournal of Biomedical Materials Research, 56: 257-260. 